Pacific Journal of Mathematic 


\title{
ON POLYNOMIAL INVARIANTS OF FIBERED 2-KNOTS
}

\author{
KoUHeI AsANo AND KATSUYUKI YoshIKAWA
}

\begin{abstract}
Given any polynomial $\lambda(t)=\sum_{j=0}^{m} c_{j} t^{j}$ satisfying the conditions that $c_{j}$ is an integer, $\lambda(1)= \pm 1, c_{0}=1$ and $c_{m}= \pm 1$, we will construct a fibered 2-knot in the 4-sphere with the invariants $\left\{\lambda_{i}^{q}(t)\right\}$ such that $\lambda_{1}^{q}(t)=\lambda(t)$ and $\lambda_{\imath}^{q}(t)=1$ for $i>1$ and $q=1,2$.
\end{abstract}

1. Introduction. An n-knot $K$ is a smooth submanifold of the $(n+2)$-sphere $S^{n+2}$ which is homeomorphic to $S^{n}$. By the exterior of $K$, we mean the complement of an open tubular neighborhood of $K$ in $S^{n+2}$. If the exterior of $K$ fibers over a 1 -sphere, $K$ is called a fibered n-knot.

Let $E$ be the exterior of an $n$-knot and $\widetilde{E}$ the infinite cyclic covering of $E$ with $\langle t\rangle$ as the covering transformation group. Let $\Lambda$ denote the integral group ring of $\langle t\rangle$ and $\Gamma=\Lambda \otimes_{z} Q$ the rational group ring of $\langle t\rangle$. Since $\Gamma$ is a principal ideal domain, $H_{q}(\widetilde{E}, Q) \cong$ $\Gamma / \lambda_{1}^{q}(t) \oplus \cdots \oplus \Gamma / \lambda_{r_{q}}^{q}(t)$. In this decomposition, we can take $\lambda_{2}^{q}(t)$ so that

(i) $\lambda_{i}^{q}(t)$ is a primitive element and $\lambda_{i+1}^{q}(t) \mid \lambda_{i}^{q}(t)$ in $\Lambda$. Then $\left\{\lambda_{i}^{q}(t): 1 \leqq i \leqq r_{q}\right\}$ are called the polynomial invariants of $K$ in dimension $q$, for $1 \leqq q \leqq n$ [3], [6], [7].

In [7], it is shown that polynomial invariants $\left\{\lambda_{i}^{q}(t): 1 \leqq i \leqq r_{q}\right.$, $1 \leqq q \leqq n$ of a fibered $n$-knot have the following properties:

(ii) If $\lambda_{i}^{q}(t)=\sum_{j=0}^{m} c_{j} t^{j}$, then $c_{0}= \pm 1$ and $c_{m}= \pm 1$.

(iii) $\lambda_{i}^{q}(1)= \pm 1$.

(iv) $\lambda_{i}^{q}(t)=\varepsilon t^{\alpha} \lambda_{i}^{n-q+1}\left(t^{-1}\right), \varepsilon= \pm 1$ and $\alpha$ is an integer.

(v) If $n=2 q-1, q$ is even, $\Delta(t)=\lambda_{1}^{q}(t) \cdots \lambda_{r_{q}}^{q}(t)$ is in normal form, i.e., $\Delta(t)=\Delta\left(t^{-1}\right)$ and $\Delta(1)>0$, then $\Delta(-1)$ is an odd square.

Furthermore, the family $\left\{\lambda_{i}^{q}(t)\right\}$ satisfying (i)-(v) can be realized as the invariants of a fibered $n$-knot, if $\lambda_{1}^{1}(t)=\lambda_{1}^{n}(t)=1$. In this paper, we will prove that

THEOREM. Given any polynomial $\lambda(t)=\sum_{j=0}^{m} c_{j} t^{j}$ satisfying $\lambda(t) \epsilon$ $\Lambda, \lambda(1)= \pm 1, c_{0}=1$ and $c_{m}= \pm 1$, there exists a fibered 2-knot in the 4-sphere with the invariants $\left\{\lambda_{i}^{q}(t)\right\}$ such that $\lambda_{1}^{q}(t)=\lambda(t)$ and $\lambda_{i}^{q}(t)=$ 1 , for $i>1$ and $q=1,2$.

Using our theorem and the argument in [7], we can show that, for given family $\left\{\lambda_{i}^{q}(t)\right\}$ which satisfy (i)-(v), there is a fibered $n$-knot with $\left\{\lambda_{i}^{q}(t)\right\}$ as its invariants. 
The authors wish to express their gratitude to Prof. A. Kawauchi for helpful suggestions.

2. Proof of Theorem. Let $V_{m}=B^{4} \cup \bigcup\left\{h_{i}^{(1)}: 1 \leqq i \leqq m\right\}$, where $B^{4}$ is a 4-ball and $h_{i}^{(1)}$ is a 1-handle. Then $\pi_{1}\left(V_{m}\right)$ is a free group freely generated by the elements $x_{1}, \cdots, x_{m}$ corresponding to $h_{1}^{(1)}, \cdots$, $h_{m}^{(1)}$, respectively. By $\varphi$, we denote an automorphism of $\pi_{1}\left(V_{m}\right)$ defined by

$$
\varphi\left(x_{i}\right)= \begin{cases}x_{i+1}, & 1 \leqq i \leqq m-1 \\ \left(x_{1}^{r_{0}} x_{2}^{c_{1}} \cdots x_{m}^{c_{m-1}}\right)^{-c_{m}}, & i=m\end{cases}
$$

Clearly, there exists an autohomeomorphism $\hat{\rho}$ of $V_{m}$ which induces the automorphism $\varphi$ of $\pi_{1}\left(V_{m}\right)$. Without loss of generalities, we may assume that $\phi$ has a fixed point $p$ in $\partial V_{m}$. Let $X$ be the 5-manifold obtained from $V_{m} \times[0,1]$ by identifying $V_{m} \times\{0\}$ and $V_{m} \times\{1\}$ via a homeomorphism $\hat{\varphi}$. More precisely, $X$ is the quotient of $V_{m} \times[0,1]$ by the equivalence relation $(x, 0) \sim(\hat{\varphi}(x), 1)$.

We can show that $\pi_{1}(X)$ has a presentation

$$
\left\langle t, x_{1}, \cdots, x_{m}: t x_{1} t^{-1} x_{2}^{-1}, \cdots, t x_{m-1} t^{-1} x_{m}^{-1}, t x_{m} t^{-1}\left(x_{1}^{c_{0}} \cdots x_{m}^{c_{m-1}}\right)^{c_{m}}\right\rangle \text {. }
$$

As in [5], $H_{1}(\tilde{X}, Q)$ is isomorphic to $\Gamma / \lambda(t)$, as a $\Gamma$-module, where $\tilde{X}$ denotes the infinite cyclic covering of $X$ with $\langle t\rangle$ as the covering transformation group. Adding a 2-handle $H_{0}^{(2)}$ to $X$ along a simple closed curve $\alpha=p \times[0,1] / \sim$ representing $t$ in $\pi_{1}(X)$, we obtain a simply connected 5-manifold $Y$. We will show that $Y$ is homeomorphic to a 5-ball.

Let $H_{i}^{(2)}=h_{i}^{(1)} \times[0,1 / 2] / \sim, H_{i}^{(1)}=h_{i}^{(1)} \times[1 / 2,1] / \sim$, for $1 \leqq i \leqq m$, $H_{0}^{(1)}=B^{4} \times[0,1 / 2] / \sim$ and $H_{0}^{(0)}=B^{4} \times[1 / 2,1] / \sim$. Then

$$
Y=H_{0}^{(0)} \cup \bigcup\left\{H_{i}^{(1)}: 0 \leqq i \leqq m\right\} \cup \bigcup\left\{H_{i}^{(2)}: 0 \leqq i \leqq m\right\},
$$

is a handle decomposition of $Y$ such that $H_{i}^{(j)}$ is a $j$-handle.

Let $W_{m+1}=H_{0}^{(0)} \cup \bigcup\left\{H_{i}^{(1)}: 0 \leqq i \leqq m\right\}$. If we denote the elements of $\pi_{1}\left(W_{m+1}\right)$ corresponding to $H_{0}^{(1)}, H_{1}^{(1)}, \cdots, H_{m}^{(1)}$ by $t, x_{1}, \cdots, x_{m}$, respectively, $\pi_{1}\left(W_{m+1}\right)$ is a free group generated by $t, x_{1}, \cdots, x_{m}$. For $1 \leqq i \leqq m$, the attaching sphere of $H_{i}^{(2)}$ represents $t x_{i} t^{-1} \varphi\left(x_{i}\right)^{-1}$.

The following transformations of a presentation $\left\langle y_{1}, \cdots, y_{s}: r_{1}\right.$, $\cdots, r_{t}>$ are called Andrews-Curtis moves [1], [2], [4]:

(i) Replace $r_{i}$ by $r_{i}^{-1}$.

(ii) Replace $r_{i}$ by $w r_{i} w^{-1}$, where $w$ is a word in $y_{1}, \cdots, y_{s}$.

(iii) Replace $r_{i}$ by $r_{i} r_{j}$, for $i \neq j$.

(iv) Add a generator $y$ and a relator $y w^{-1}$, where $w$ is a word in $y_{1}, \cdots, y_{s}$.

(v) Inverse transformation of (iv). 
It is not difficult to show that a presentation

$$
\left\langle t, x_{1}, \cdots, x_{m}: t, t x_{1} t^{-1} x_{2}^{-1}, \cdots, t x_{m-1} t^{-1} x_{m}^{-1}, t x_{m} t^{-1}\left(x_{1}^{c_{0}} \cdots x_{m}^{c_{m-1}}\right)^{c_{m}}\right\rangle
$$

can be transformed to the trivial presentation by Andrews-Curtis moves. Hence one can slide 2-handles $\left\{H_{i}^{(2)}\right\}$ to cancel 1-handles $\left\{H_{i}^{(1)}\right\}$ [1]. Thus $Y$ is homeomorphic to a 5-ball.

Let $B^{3}$ be a co-core of $H_{0}^{(2)}$. Then $H_{0}^{(2)}$ can be considered as a tubular neighborhood of $B^{3}$ in $Y$. Hence the exterior of a 2-knot $\partial B^{3}$ in $\partial Y$ is $\left.\left.\overline{\left(\partial X-\left(\partial X \cap H_{0}^{(2)}\right.\right.}\right)\right)$. Since $\left.\left.\overline{\left(\partial X-\left(\partial X \cap H_{0}^{(2)}\right.\right.}\right)\right)$ fibers over a 1 -sphere and

$$
\pi_{1}(X) \cong \pi_{1}(\partial X) \cong \pi_{1}\left(\overline{\partial X}-\left(\overline{\partial X \cap H_{0}^{(2)}}\right)\right),
$$

the proof is completed.

\section{REFERENCES}

1. J. J. Andrews and M. L. Curtis, Free groups and handle bodies, Proc. Amer. Math. Soc., 16 (1965), 192-195.

2. R. Kirby, Problems in low dimensional manifold theory, Proceedings of Symposia in Pure Mathematics 32, Part 2, Amer. Math. Soc., (1978), 273-312.

3. J. Levine, Polynomial invariants of knots of codimension two, Ann. of Math., 84 (1966), 537-554.

4. - Some results on higher dimensional knot groups, Lecture Notes in Math. 685, Springer-Verlag, (1978), 243-269.

5. E. S. Rapaport, On the commutator subgroup of a knot group, Ann. of Math., 71 (1960), 157-162.

6. Y. Shinohara and D. W. Sumners, Homology invariants of cyclic coverings with application to links, Trans. Amer. Math. Soc., 163 (1972), 101-121.

7. D. W. Sumners, Polynomial invariants and the integral homology of coverings of knots and links, Invent. Math., 15 (1972), 78-90.

Received November 3, 1980.

KWANSEi GakUin University,

NISHINOMIYA, HYOGO 662,

JAPAN 



\section{PACIFIC JOURNAL OF MATHEMATICS}

EDITORS

DONALD BABBITT (Managing Editor)

University of California

Los Angeles, CA 90024

Hugo RossI

University of Utah

Salt Lake City, UT 84112

C. C. MOORE and ANDREW OGG

University of California

Berkeley, CA 94720

\section{J. DugundjI}

Department of Mathematics

University of Southern California

Los Angeles, CA 90007

R. FINN and J. MILGRAM

Stanford University

Stanford, CA 94305

\section{ASSOCIATE EDITORS}
R. ARENS
E. F. BECKENBACH
B. H. NEUManN
F. WOLF
K. YoSHIDA

\section{SUPPORTING INSTITUTIONS}

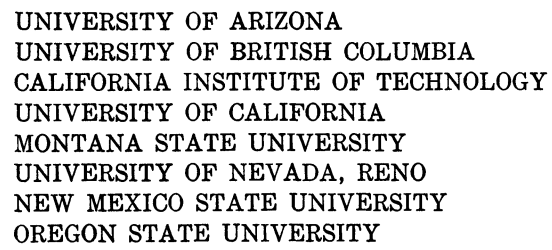

UNIVERSITY OF ARIZONA

UNIVERSITY OF BRITISH COLUMBIA

CALIFORNIA INSTITUTE OF TECHNOLOGY

UNIVERSITY OF CALIFORNIA

MONTANA STATE UNIVERSITY

UNIVERSITY OF NEVADA, RENO

NEW MEXICO STATE UNIVERSITY

OREGON STATE UNIVERSITY

\author{
UNIVERSITY OF OREGON \\ UNIVERSITY OF SOUTHERN CALIFORNIA \\ STANFORD UNIVERSITY \\ UNIVERSITY OF HAWAII \\ UNIVERSITY OF TOKYO \\ UNIVERSITY OF UTAH \\ WASHINGTON STATE UNIVERSITY \\ UNIVERSITY OF WASHINGTON
}

The Supporting Institutions listed above contribute to the cost of publication of this Journal, but they are not owners or publishers and have no responsibility for its content or policies.

Mathematical papers intended for publication in the Pacific Journal of Mathematics should be in typed form or offset-reproduced, (not dittoed), double spaced with large margins. Please do not use built up fractions in the text of the manuscript. However, you may use them in the displayed equations. Underline Greek letters in red, German in green, and script in blue. The first paragraph or two must be capable of being used separately as a synopsis of the entire paper. Please propose a heading for the odd numbered pages of less than 35 characters. Manuscripts, in triplicate, may be sent to any one of the editors. Please classify according to the scheme of Math. Reviews, Index to Vol. 39. Supply name and address of author to whom proofs should be sent. All other communications should be addressed to the managing editor, or Elaine Barth, University of California, Los Angeles, California, 90024.

50 reprints to each author are provided free for each article, only if page charges have been substantially paid. Additional copies may be obtained at cost in multiples of 50 .

The Pacific Journal of Mathematics is issued monthly as of January 1966. Regular subscription rate: $\$ 102.00$ a year (6 Vols., 12 issues). Special rate: $\$ 51.00$ a year to individual members of supporting institutions.

Subscriptions, orders for numbers issued in the last three calendar years, and changes of address shoud be sent to Pacific Journal of Mathematics, P.O. Box 969, Carmel Valley, CA 93924, U.S.A. Old back numbers obtainable from Kraus Periodicals Co., Route 100, Millwood, NY 10546.

\section{PUBLISHED BY PACIFIC JOURNAL OF MATHEMATICS, A NON-PROFIT CORPORATION}

Printed at Kokusai Bunken Insatsusha (International Academic Printing Co., Ltd.). 8-8, 3-chome, Takadanobaba, Shinjuku-ku, Tokyo 160, Japan. 


\section{Pacific Journal of Mathematics}

\section{Vol. 97, No. $2 \quad$ February, 1981}

Patrick Robert Ahern and N. V. Rao, A note on real orthogonal measures . . . . . 249

Kouhei Asano and Katsuyuki Yoshikawa, On polynomial invariants of fibered

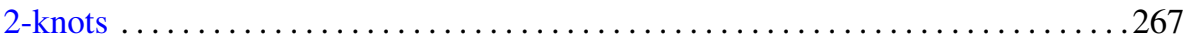

Charles A. Asmuth and Joe Repka, Tensor products for $S L_{2}(\mathscr{K})$. I.

Complementary series and the special representation

Gary Francis Birkenmeier, Baer rings and quasicontinuous rings have a

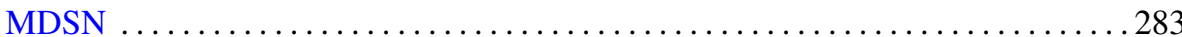

Hans-Heinrich Brungs and Günter Törner, Right chain rings and the generalized

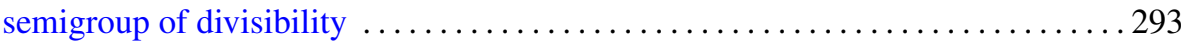

Jia-Arng Chao and Svante Janson, A note on $H^{1} q$-martingales . . . . . . . . . 307

Joseph Eugene Collison, An analogue of Kolmogorov's inequality for a class of

additive arithmetic functions

Frank Rimi DeMeyer, An action of the automorphism group of a commutative ring on its Brauer group

H. P. Dikshit and Anil Kumar, Determination of bounds similar to the Lebesgue

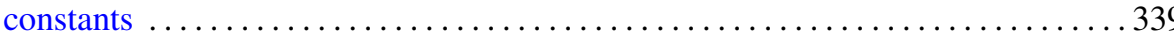

Eric Karel van Douwen, The number of subcontinua of the remainder of the plane

D. W. Dubois, Second note on Artin's solution of Hilbert's 17th problem. Order spaces

Daniel Evans Flath, A comparison of the automorphic representations of GL(3) and its twisted forms

Frederick Michael Goodman, Translation invariant closed $*$ derivations

Richard Grassl, Polynomials in denumerable indeterminates

K. F. Lai, Orders of finite algebraic groups

George Kempf, Torsion divisors on algebraic curves

Arun Kumar and D. P. Sahu, Absolute convergence fields of some triangular matrix methods

Elias Saab, On measurable projections in Banach spaces

Chao-Liang Shen, Automorphisms of dimension groups and the construction of AF algebras

Barry Simon, Pointwise domination of matrices and comparison of $\Phi_{p}$ norms

Chi-Lin Yen, A minimax inequality and its applications to variational inequalities

Stephen D. Cohen, Corrections to: "The Galois group of a polynomial with two indeterminate coefficients"

Phillip Schultz, Correction to: "The typeset and cotypeset of a rank 2 abelian group"

Pavel G. Todorov, Correction to: "New explicit formulas for the $n$th derivative of composite functions"

Douglas S. Bridges, Correction to: "On the isolation of zeroes of an analytic function" 